\title{
ASSIM FALOU VALÉRY: A EXPECTATIVA MELÓDICA
}

\section{THUS SPOKE VALÉRY: MELODIC EXPECTATION}

\section{Daniel de Oliveira Gomes"}

REsumo: Este ensaio trabalha, essencialmente, os escritos de Paul Valéry sobre Leonardo da Vinci. Ocorreria, em Valéry, uma aproximação inevitável com a característica melódica com a qual Nietzsche intui o desmoronamento da metafísica. Por sua vez, é possível compreendermos alguns dos ensinamentos de Maurice Blanchot, que sabidamente incluía especialmente a Valéry no seu rol seleto de leituraschave. Queremos, enfim, mostrar como a transversalidade e a errância musical do pensamento já está operada tanto na obsessão pela paisagem em Da Vinci quanto na repetição metodológica dos escritos de Nietzsche, Blanchot e Valéry.

PALAVRas-chave: Blanchot. Valéry. Transversalidade. Errância.

Aвstract: This essay discusses Paul Valery's writings about Leonardo da Vinci. In Valery's writing there is an inevitable proximity with the melodic characteristic with which Nietzsche predicted the collapse of metaphysics. In turn, it is possible to understand some of the teachings of Maurice Blanchot, who is known to have included Valery in his list of selected key-readings. Finally, we would like to show how transversality and the musical wandering of the thought is already present in both landscape obsession in Da Vinci and in the methodological repetition in the writings of Nietzsche; Blanchot and Valéry.

KEYwORDs: Blanchot. Valéry. Transversality. Wandering.

"Doutor pela UFSC. Atua no Mestrado em Linguagem, Identidade e Subjetividade - UEPG, Paraná. Email: setepratas@ hotmail.com. 
Será possivel que o filósofo pense que uma ética ou uma Monadologia sejam coisas mais sérias que uma suíte em ré menor? (Paul Valéry, Léonard et les philosophes. Lettre à Léo Ferrero).

1. VALÉry, Nietzsche, Blanchot

O presente artigo visa especular sobre a questão do conhecimento estético que é abordado por Paul Valéry em alguns de seus ditos sobre Leonardo Da Vinci. Queremos compartilhá-lo à luz dos ensinamentos de Maurice Blanchot, que sabidamente incluía especialmente a Valéry no seu rol seleto de leituras-chave. E queremos expor como ocorreria um acontecimento melódico (em uma constante propagação) no gesto de reflexão do próprio Valéry. De maneira que aquilo mesmo que é reivindicado como potência de liberdade na produção do saber acaba sendo operado repetitivamente por ele ao ler $\mathrm{Da}$ Vinci. Se por um lado, Blanchot postula um pensamento descontínuo, que nos possibilita a passagem à experiência do Fora, Valéry (2006) propõe, na sua Introdução ao método de Leonardo da Vinci-recém-reimpresso em edição bilíngue, no Rio de Janeiro - a redundância de um pensamento da transversalidade que já pode ser lida desde seu objeto.

Pensaremos no modo como Valéry (2006) constrói o seu texto e a questão que ele lerá em Da Vinci é, obviamente, a do constructo. Primeiramente, gostaríamos de lembrar que em sua "Introdução ao Método de Leonardo da Vinci”, o autor se interessava pela questão de como uma obra se produz pela repetição, reprodução. Falará muito da estética da pintura, altamente ensimesmada no talento de Da Vinci, mas, em alguns momentos, atravessa pela demanda da música. Torna a concepção de música muitíssimo abrangente, até mais do que a própria metáfora da pintura, na ordem das "construções humanas". Para ele:

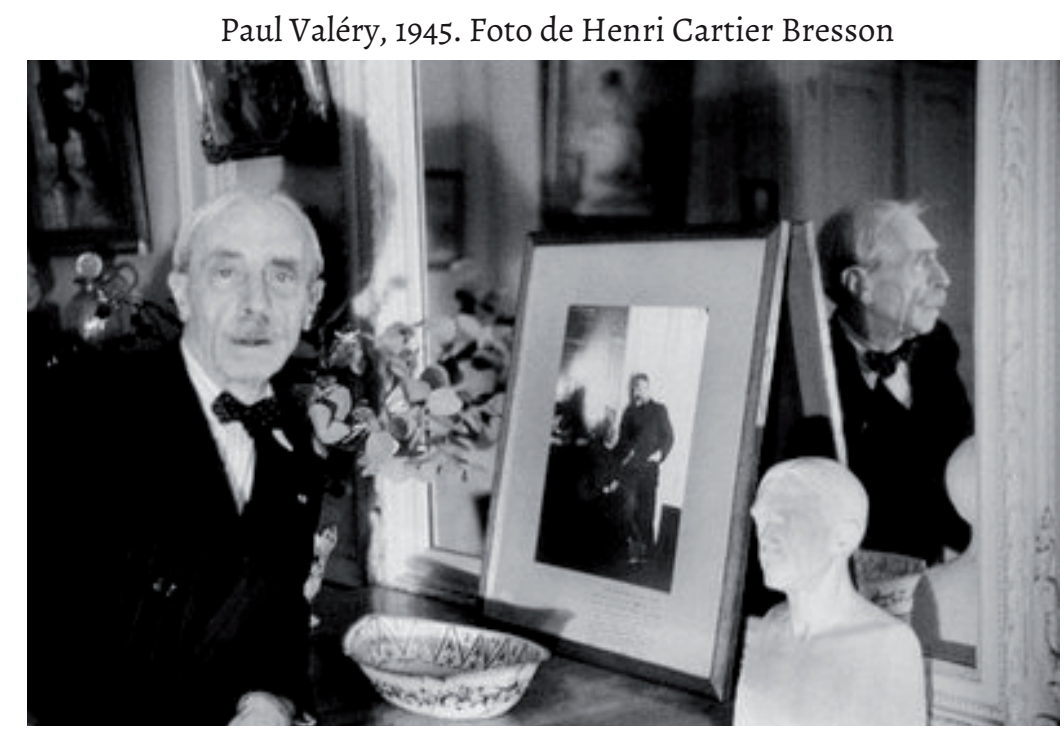

Disponível em: http://www.magnumphotos.com. Acesso em o2 de jan de 2013. 
O construir existe entre um projeto ou uma visão determinada e os materiais que escolhemos. Substitui-se uma ordem inicial por outra, quaisquer que sejam os objetos que ordenemos. São pedras, cores, palavras, conceitos, homens, etc., a natureza particular deles não muda as condições gerais dessa espécie de música em que ela representa ainda apenas o papel do timbre, se prosseguirmos com a metáfora. $\mathrm{O}$ espantoso é sentir às vezes a impressão de justeza e de consistência nas construções humanas, feitas de aglomerações de objetos aparentemente irredutíveis, como se aquele que os dispôs houvesse conhecido as suas mais secretas afinidades. Mas o espantoso supera tudo quando se percebe que o autor, na imensa maioria dos casos, é incapaz por si mesmo de explicar os caminhos seguidos e quando ele é detentor de um poder cujos meios ignora. (VALÈRY, 2006, p. 69)

Pois bem, voltaremos depois a essa questão ampla da construção musical. Vamos, agora, à causa filosófica. Ele explana sobre a Filosofia de um modo que muito se assemelha a alguns comentários que Nietzsche fez em vários aforismos. Em certo momento de "Leonardo e os Filósofos", falará em como a utopia de fazer o pensamento falar é um ato improfícuo e atirará pedras no problema da filosofia como um meio sutil de repetição, ou de "reconhecimento do conhecimento".

Os filósofos, todavia, esforçaram-se por relacionar a sua linguagem à sua vida profunda, reclassificá-la, completá-la um pouco de acordo com as necessidades de sua experiência solitária, para torná-la um meio mais sutil, mais seguro de conhecer e reconhecer seu conhecimento. (VALÉRY, 2006, p. 243.)

Se Valéry critica a filosofia no aspecto da obsessão da redundância com relação a si mesma, onde aquilo que se busca é apenas o caminho mais seguro para fazer reconhecer o que já se conhece, em termos textuais, vejamos, agora, o que sustentava o filósofo alemão em A Gaia Ciência:

Recojo esta explicación del arroyo; he oído a um hombre del pueblo decir: 'Me ha conocido'. Y me pregunto: ¿Qué es lo que en realidad entiende el pueblo por conocer? ¿Qué quiere cuando desea alcanzar el conocimineto de algo? Pues nada más que esto: que algo extraño se reduzca a algo conocido. ¿entendemos algo más por conocimento los filósofos? Lo conocido es aquello a que estamos acostumbrados y que, por lo mismo, no nos choca: nuestras tareas cotidianas, la regla a que estamos sujetos, todo aquello que es familiar para nosotros. ¿ Cómo? ¿ Nuestra necessidad de conocer será precisamente necessidad de algo conocido? Será el deseo de descubrir entre todas las cosas extrañas, desacostumbradas, inciertas, algo que conocido ya no nos inquiete? ¿Será el instinto del miedo lo que nos impulsa a conocer? La satisfacción del que conoce, ¿será el júbilo de la seguridad recobrada? Um filósofo da por conocido al mundo cuando há conseguido reducirle a la idea. Mas ¿no será porque la idea es para el cosa conocida $y$ habitual? ¡Vaya noramala esta moderación de los que persiguen el conocimiento! ¡Examinad desde este punto de vista sus principios y las soluciones que dan a los problemas del mundo! Cuando hallan en las cosas, o detrás de las cosas, algo que desgraciadamente conocemos demasiado, 
como por ejemplo, nuestra tabla de multiplicar, nuestra lógica, nuestra voluntad o nuestro deseo, iqué grito de alegria lanzan! Su norma es que lo conocido es reconocido. (NIETZSCHE, 2000, p. 230.)

Ambos recriminam a caça antiga pelo conhecimento regularizada desde a metafísica aristotélica, vislumbrando o recurso pela fruição e o prazer do perpetrar filosófico como uma obra de arte. Entretanto, se Nietzsche é mais calamitoso ou agudo, por sua vez, Valéry falará de uma viável arte das ideias, sustentando certa esperança estética no surgimento de uma nova filosofia que salte de si mesma. Tal como a especulação lúdica e egocêntrica da abstração matemática flexibilizou-se para cunhar as condições de possibilidade para o trabalho do físico, por exemplo, haveria uma brecha no coração da metafísica moderna para se resgatar certo modelo, o que seria o Leonardo filósofo. Já Nietzsche, no fim do séc. XIX, por sua vez, - como diria Foucault em "As Palavras e as Coisas" - preocupava-se mais em realmente queimar “(...) para nós, e antes mesmo que tivéssemos nascido, as promessas mescladas da dialética e da antropologia." (FOUCAULT, 1990, p. 278). Nietzsche é, assim, aquele cuja preocupação é realmente pós-utópica: incendiar a História, o continuísmo metafísico, inflamar o atravancamento antropológico do pensar, e, nisso, abria um espaço filosófico-filológico desmistificando nossa velha solicitude para com o humanismo.

Já para Valéry (2006), descartar Leonardo do baralho dos filósofos, por falta de precisão de seus registros, teria sido uma inconsciente e oportuna operação para uma grande cifra de pensadores. Estes, na paixão "equivocada" pela precisão, empregavam a linguagem como mero fruto de suas teorizações. Mas, tal paixão pela precisão e o conhecimento do já reconhecido é coisa que justamente não ocorre tão essencialmente em Leonardo quanto pode parecer, por sua tendência engenhosa ou experimentalista. (Haverá, ao invés disso, aquela "paixão pela errância” a qual Blanchot discorria?).

Voltando à Nietzsche (2000), por mais que os espectros eugenistas totalitários da Alemanha tenham acabado por atenuar a lição de Zaratusta para nós ocidentais, em rigor, para Nietzsche, que nunca foi um antissemita, a noção de super-homem apontava um caráter mais exotérico, errante, quando profetizava que a missão do pensamento seria a intuito mystica (ASTOR, p. 219). E esta intuito mystica vem a ser, em certa medida, aquilo que Valéry assinala em Da Vinci. Como corrobora o biógrafo de Nietzsche, Dórian Astor, inspirado por Peter Gast, neste momento de Zaratustra, ocasião da morte de seu grande ídolo e amigo Wagner, quando Nietzsche justamente "intui" como desmascarar o padrão da filosofia europeia, "seu modelo é musical e mais precisamente sinfônico" (ASTOR, 2013, p. 219). E é Zaratustra o portador do fardo e da certeza do eterno retorno. Trata-se de uma certeza melódica (chegada de um filósofo tão revolucionário quanto Da Vinci, um filósofo amante da música que fora um pianista frustrado, porém excelente improvisador). Incerta sinfonia daquele que queria fazer música com o pensamento, quem sabe tal como Da Vinci fizera pintura com o pensamento. $\mathrm{O}$ 
pensamento (incomunicável) do eterno retorno da vida é o fardo pesado da revelação de nossa imanência infinita, é a recusa de qualquer teleologia, onde tudo é poderosamente circular, repetitivo, o que obviamente se diferencia de uma concepção mecanicista do tempo e da natureza. (Ou seja, de Da Vinci que, por sua vez, jaz obviamente amarrado nas bases do racionalismo, do mecanicismo, do experimentalismo). $O$ eterno retorno do mesmo torna-se base da infinita importância do saber, do comportamento, do pensar, do porvir. Isto comprova, nesta fase "mística" de intuição melódica do filósofo alemão, que todo saber advém enquanto decorrência de uma concepção de vida fundada na hipótese da vontade de poder. O puro saber não é tudo, não é nada.

No acontecimento de sentido onde para Leonardo "o saber não é tudo" (Valéry, 2006, p. 119), residiria o ponto em que a especulação pode ser propriamente ethopoiética (diria Foucault), posto que se nota a transversalidade de Da Vinci, auctor aventuralmente absoluto. Pintor que, não raro, deixava seus afrescos incompletos. Construtor, criador, desenhista, anatomista, engenheiro militar (e, afirma-se, como Nietzsche era também músico, com a diferença que compunha seus próprios instrumentos musicais e neles meditava sobre os modelos que pintava). Ele suga do imprevisto as ocasiões do saber. Não há presciência, olhar prévio, anterioridade ou lugar, segundo Valéry (2006). Não há apenas quantificação, mas traços de um "sentimento" da errância. Para Da Vinci, poderíamos afirmar que a questão não seria propriamente a obsessão do espaço, mais da paisagem?
Aliás, a paisagem não é o espaço, e sim uma qualidade do espaço. É esse o sentido da observação de Paul Valéry, admirador de Leonardo e adepto da pintura como cosa mentale: $O$ desenvolvimento da paisagem parece coincidir com uma diminuição singularmente marcada da parte intelectual da arte (Degas, dança, desenho, Cosac Naify, 2003). A paisagem é qualificável, não quantificável; ela não lida com a medida, mas com o sentimento. (AUMONT, 2007, p.230)

Há, sim, entre-lugar: onde o poder profético é o que lhe importa, implicando, em seu trabalho, ainda mais que o saber ${ }^{1}$. $O$ poder nele permanece na inseparabilidade entre construção e verdade. E é isto que Leonardo põe em movimento prático, dentro de seu próprio contexto, naturalmente. Se para Blanchot (2005), a linguagem do pensamento é, por excelência, a própria palavra poética, tentamo-nos a dizer que, para Valéry, atingir o belo só se daria pelo próprio domínio do belo, de modo que resumir uma obra de arte seria perder-lhe o essencial. A estética, como conhecimento, não poderia ser. Ela simplesmente está fadada à incidência pela poesia, que forneceria a fuga potente da manobra das palavras; ou pela música.

Ouso dizer que isso é real (infelizmente). Durante anos, o escritor cessou de escrever. E, como que para tornar ainda mais fatal uma tal interrupção, ele ocupou seu tempo com outras artes: a

\footnotetext{
1 "A fala profética é uma fala errante que volta à exigência originária de um movimento, opondo-se a toda estabilidade, toda fixação a um enraizamento que seria repouso" (Blanchot, 2005, p. 114)
} 
pintura, o desenho, que mais eu sei ?talvez a música.

Como ele foi um dia reconduzido à exigência de escrever sobre a qual nem a dor, nem o juramento tácito, nem o vazio perpétuo conseguiram triunfar? É que talvez ele tenha se dado conta de que, para não mais escrever, seria preciso ainda escrever, escrever sem fim até o fim ou a partir do fim.

Não há brancos senão se há negro, silêncio senão se a palavra e o barulho se produzem para cessar. (BLANCHOT, 2002, p. $20^{2}$ )

\section{Ostinato}

"Ó Ostinato, ó amarga beleza." (BLANCHOT, 2002)

Uma obra muito modelar e didática, a Enciclopedia de la Musica, organizada por Frank Onnen (1967), na Holanda (Elseviers Enciclopedie Van de Muziek), apresenta-nos o seguinte verbete sobre a anotação do "Ostinato":

OSTINATO (italiano = obstinado), tema que vuelve continuamente, principalmente en el bajo. Algunas formas musicales, como la chacona y el pascalle, están basadas en el principio musical del ostinato (ONNEN, 1967, p. 222)

Ostinato seria a variação cíclica, repetitiva, de um esquema melódico no interior de uma peça musical, uma frase, uma

\footnotetext{
${ }^{2}$ Tradução do Núcleo de Estudos Blanchotianos e do Pensamento do Fora (CNPq), ainda não publicada, cedida por Prof. Dr. Eclair Almeida Filho (UNB)
}

repassagem, por exemplo, tal como é muito utilizada por Schumann, Bach, Bartok, na música erudita e na tradição litúrgica, mas também muito explorada no que há de "profano" nas raízes dos gêneros, por exemplo, do Jazz e do Blues, e como base da mão esquerda de pianistas de jazz em momentos de improvisos, citemos aqui Keith Jarrett, em sua famosa performance The Köln Concert, em 1975, na Alemanha³.

Partitura do pianista americano K. Jarrett, onde impera o Ostinato.
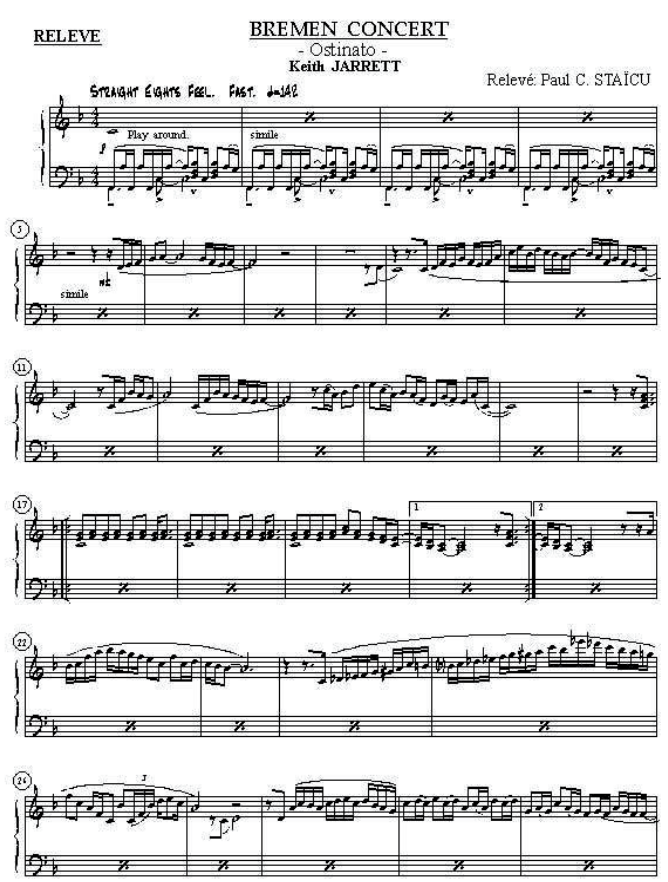

Fonte: www.keithjarrett.org/transcriptions

\footnotetext{
${ }^{3}$ Jarret diria: “(...) Eu não acredito em Arte. Neste sentido, não sou um artista. Acredito em Música, entendida como algo que sempre esteve aqui e bem antes de nós. Neste sentido, possivelmente, eu não sou um músico. Não acredito em Vida, mas quem considere com real profundidade a questão também encontrará a mesma chave. Não acredito que eu possa criar, mas sim que possa ser um canal para o criativo. (...)" Estas palavras escreveu Keith Jarrett no encarte da gravação de Solo Concerts Bremen/ Lausanne (1973).
} 
Uma das influências de Jarrett: Béla Bartok, (pianista húngaro, início do séc. XX). Veja-se repetição de frases em claves distintas.

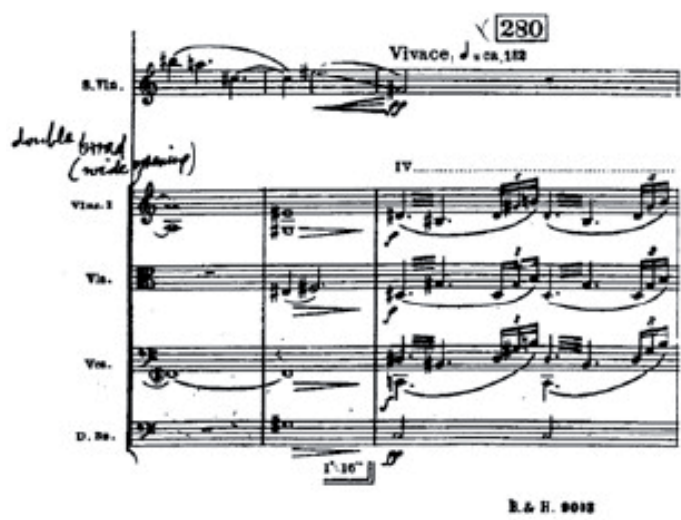

Ex. 3. Volin Concerto, 1937-38. Excerpt from the the galley proofs of the first movement from the Boosey \& Hawkes edition.

Fonte: www.docfoc.com/category/Documents

Nestes casos, o que proporcionaria não apenas uma situação de experiência desgastante da audição, mas, ao contrário, uma possibilidade excêntrica e até mesmo mística para os ouvintes; tome-se como exemplo a música emblemática de John Coltrane, ou muitos dos riffs pianísticos obcecados de estilo de Thelonious Monk (tomemos um desses jazzistas e, aliás, escolheríamos um bom exemplo de que o recurso do ostinato pode ser uma potência para a fuga do arquétipo e não propriamente a sua construção pelo processo de repetição). Esta figura musical pode ser tão amplamente tratada, vendo-a como "processo de circularidade melódica" que não deixou de se tornar um tema de passagem obrigatório em Blanchot, em "Uma voz vinda de alhures". Blanchot, em determinado momento, recai na necessidade de discorrer um breve capítulo acerca do Ostinato. Capítulo este onde agrega o mote etimológico italiano (obstinado) com o modo com o qual Paul Valéry (2006), ao seu estilo, deixa-se fascinar pelo rigor obstinado, ostinato, de Leonardo da Vinci.

Creio que é preciso falar de "Ostinato", que seria preciso falar dele, mas privado de palavras, numa linguagem que me obceca me fazendo ausência.

Ostinato é uma anotação musical. É um tema sem variações, um motivo acalorado que revém e não revém. Alban Berg o ouve em Schumann, e eu também o ouço como essa nota única que não cessava de retumbar em sua cabeça sem poder se desenvolver.

É também «o obstinado rigor » de Leonardo da Vinci do qual o jovem Paul Valéry sofreu o encantamento apenas se prometendo de não manter dele senão o rigor. (p. 20)

Para Blanchot (2002), a figura do ostinato é pertinente, ao citar, dentre outros, a Valéry, posto sua concepção estética da obra como infinita, algo que sustenta muito bem em todo “O Espaço Literário”. Uma vez sempre infinita, a obra é uma procura incessante, considerando que uma obra-prima não é jamais a busca da perfeição pelo viés do repetitivo - do tentar e errar, tentar e acertar - rumo à continuidade e o uniforme. A obra é sim, para ele, o próprio assentimento musical da errância. E a errância, como tal, seria o que para, por exemplo, Leonardo Da Vinci (e/ou Nietzsche), funcionava não raro como a fonte de suas hipóteses, o que o leva pragmaticamente a suspeitar da infalibilidade que repousa a geral confiança científica, 
segundo Valèry (2006). O supra-valor do cogito ergo sum é assediado violentamente pela lição de liberdade de Da Vinci, e vem a ser por isto que Valéry considerará a filosofia como um gênero não muito afastado da poesia, e porque não dizer, da dança, da música ${ }^{4}$. A errância, no domínio da filosofia tradicional que está no alvo da sua crítica, condiz em geral com um espaço opaco onde nada faz sentido. Isso vem a ser um processo totalmente distinto das operações da música, do improviso, da fruição sonora, o que explica o porquê da filosofia constantemente negar o arbitrário; até quem sabe surgirem as condições do aparecimento de Nietzsche, Valéry, e do pós-estruturalismo, digamos. Não apenas o músico, mas se dirá que o artista em geral passa da forma ao conteúdo e vice-versa com muito mais liberdade do que o filósofo. Isso se daria pelo fato do arbitrário e da errância oferecerem mais perigo com relação ao desconhecido. Na tentativa de suspender o convencional, buscando a preciosidade profunda do sentido, o pensador transformaria delicadamente "o segundo em um ano", necessidade de dilatar o tempo e não propriamente de habitar o tempo, fascinar-se com o tempo. O imediatismo bruto da ordem do visual (diagrama, desenho, gráfico, etc)

\footnotetext{
4 "Valéry comparou a prosa com a marcha e a poesia com a dança. Relato ou discurso, história ou demonstração, a prosa é um desfile, uma verdadeira teoria de idéias ou fatos. A figura geométrica que simboliza a prosa é a linha: reta, sinuosa, espiralada,ziguezagueante, mas sempre para diante e com uma meta precisa. Daí que os arquétipos da prosa sejam o discurso e o relato, a especulação e a história. O poema, pelo contrário, apresenta-se como um círculo ou uma esfera: algo que se fecha sobre si mesmo, universo auto-suficiente e no qual o fim é também um princípio de volta, se repete e se cria" PAZ, Octávio, "Verso e Prosa”. In: Signos em Rotação, São Paulo: Perspectiva, 1996, p.12.
}

falaria inclusive mais, muitas vezes, e mais eficazmente, que as palavras sutis quando procuram o sentido real do mundo pelo longo movimento lógico-gramatical. A estética da música, igual modo, para ele, induz intuições, lembranças e impulsos mais eficazmente. Logo, a errância cria sim sentido, cria relações até subjetivamente mais intensas. ${ }^{5}$

A errância, para Blanchot, surge como caça plural da irregularidade, do imprevisível, até mesmo do anonimato, coisas que o próprio Valéry já dava a entender em suas passagens sobre a renascença, em especial sobre a personalidade artística em Da Vinci.

A obra de arte não remete imediatamente a alguém que a teria feito. Quando ignoramos todas as circunstâncias que a prepararam, desde a história de sua criação até ao nome daquele que a tornou possível, é justamente quando ela mais se aproxima de si mesma. Está aí a sua verdadeira direção. É essa exigência que se exprime nesse superlativo que é a obra-prima. A obra-prima não está na perfeição, tal

\footnotetext{
${ }^{5}$ Podemos afirmar que, na evolução dos gêneros artísticos, tomemos a música e a escritura literária, por exemplo, como dirá Solange Ribeiro de Oliveira, a representatividade do literário passa ao presentativo, tal como a música faz o caminho inverso, de genuinamente presentativo passa ao representativo. Veja-se: “(...) A expressão musical teria acentuado e enriquecido o aspecto realista da linguagem instintiva, e a poética, o inteligível. A partir de sua separação, a música e a arte verbal teriam tido desenvolvimentos antagônicos, sem excluir encontros ocasionais. A música parte de puras abstrações formais, chegando à expressão de estados de espírito e sentimentos e, eventualmente, à tentativa de sugerir objetos e narrativas, como na música programática; a literatura, partindo do concreto, do elemento representacional, aventura-se aos poucos abandoná-lo, buscando atingir a apresentação, a relativa pureza da abstração. Daí resulta a tensão interna das duas artes, buscando ambas transcender seu elemento natural.(...)" (RIBEIRO, 2002, p.53)
} 
como essa palavra, reivindicada pela estética, o dá a entender, nem pela mestria que é do artista, não da obra. Valéry diz muito bem que a mestria é o que permite nunca terminar o que se faz. Somente a mestria, o domínio do artesão se acaba no objeto que ele fabrica. (BLANCHOT, 1987, p.221)

É sabido que os desenhos e esquemas de Leonardo eram arranjados, frequentemente, com alguns erros propositais, ou sem alguns detalhes especiais, para que apenas o próprio Leonardo soubesse alguns segredos de seus inventos e os mantivesse, muitas vezes, sob um dado poder pessoal.

Helicóptero imaginado por Da Vinci, o desenho grafa um artefato com hélices onde há dado poder pessoal de interpretação. Constam segredos omitidos no registro do invento. Fonte: PEDRETTI, "L'anatomia della 'bellezza umana" in Leonardo: L'anatomia. Carlo Pedretti, 2005.

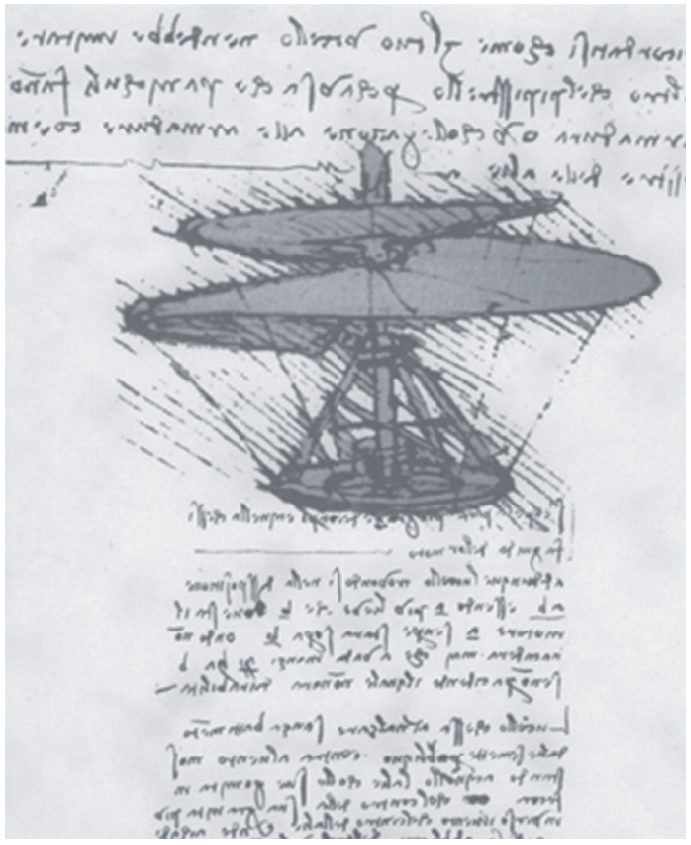

Cumpre dizer que essa pessoalidade, esta particularidade, como gesto mais do artista que geralmente do filósofo, é reiterada pela crítica ao cartesianismo que opera Valéry. Da Vinci não tinha nenhum problema com a ética do registro, ao contrário, a questão era antes estética. Não é a toa que Blanchot alude o modo como Valéry resgata e fascina-se com Da Vinci, ao falar do ostinato. Pois Valéry explica-nos que fazer o pensamento falar é um ato vão, repetição do já-sabido. Ele lê a engenhosidade e a geometria, a fisiologia e a perspectiva, naquela obstinação criativa de Da Vinci, como antes uma obsessão pictural (e mesmo musical); ou melhor, uma busca pelo poder de pintar, o poder que não funciona como simples mediação da verdade que ele buscava, simples força de registro, mas o poder como a caça melódica em si.

\section{Pulsões de Da Vinci}

Quer dizer, não seriam tão somente pulsões de uma obsessão dessas metodologias em si mesmas e para si mesmas, suas funcionalidades objetivas, porém, tudo se dá como acontecimento de um profundo desejo do bem pintar, onde o ato do pensamento está sobremodo subordinado ao enlaço estético e à arbitrariedade, em seu mais acanhado domínio de aspiração utilitária. 
Coração humano pintado por Da Vinci. Um de seus vários estudos de anatomia

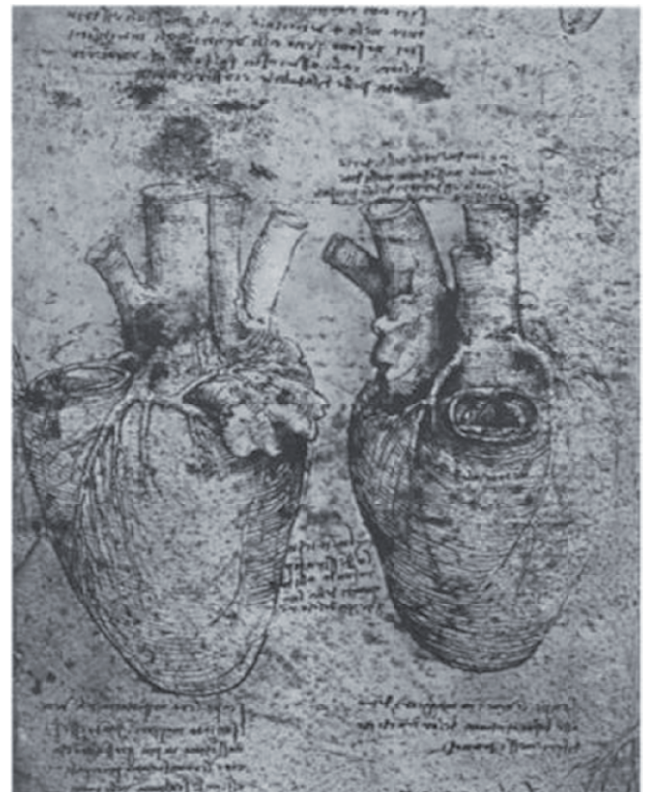

Fonte: PEDRETTI,"L'anatomia della 'bellezza umana” in Leonardo: L'anatomia. Carlo Pedretti, 2005.

O olhar que sintetiza a vontade científica e, igualmente, a vontade estética é o olhar que Valéry recupera de Leonardo. Ao afirmar que a preocupação com a pintura é a origem do lugar da filosofia para Leonardo, Valéry entende e potencializa o talento particular, a estética, (o coração e a emoção), como o leit motiv juntamente com a preocupação essencial e superficial da sua curiosidade filosófica. A primeira preocupação de Da Vinci seria uma preocupação com o texto, com o traço, com o prazer. Jamais observa a profundeza do belo na condição de mero artifício do pensar em Leonardo.

Eis portanto o que mais maravilhoso me parece em Leonardo, e que o opõe e o une aos filósofos bem mais estranhamente e mais profundamente do que tudo o que aleguei sobre ele e sobre eles mesmos. Leonardo é pintor, digo que tem a pintura por filosofia. $\mathrm{Na}$ verdade é ele mesmo quem o diz e fala da pintura como se fala da filosofia. (VALÉRY, 2006, p. 232)

Pela pintura ser a condição intrínseca de Leonardo filósofo, ele teria sido excluído monstruosamente da filosofia, com as conjeturas e epifenômenos próprios do racionalismo e dos princípios de exceção conceitual do campo filosófico, o que Valéry explana como uma revisão a se assumir, já em sua Lettre à Léo Ferrero, de 1929. Isso nos levaria a pensar: será a linguagem, em Leonardo, mais uma mediação melódica das tinturas de uma vontade de poder? Será antes isto do que apenas a interposição de uma aspiração de saber? Porque geralmente é esta aspiração imaculada de saber que se apregoa a ele, o otimismo apolíneo como pureza racional e curiosa do sujeito renascentista. O talento permaneceria como mero instrumental da versatilidade do gênio. Mas não para Blanchot ou Valéry. Teríamos, aliás, que ponderar se o que Valéry demanda não é justamente a posição nietzschiana do fugitivus errans (modo como Nietzsche assinou uma carta a Paul Rée, em 1879), a leitura dessa perigosa figura do ostinato musical, estético, fruição absoluta, dionisíaca, como fundamento espiritual em Leonardo, apagamento de Leonardo, posto que este tivesse certa "embriaguez musical" por filosofia, “a pintura por filosofia.” (2006, p. 233). 


\section{REFERÊNCIAS}

ASTOR, D. Nietzsche. Porto Alegre: LP\&M, 2013.

AUMONT, J. O olho interminável [cinema e pintura]. Trad Eloísa Araujo Ribeiro. São Paulo: Cosacnaify, 2007.

BLANCHOT, M. A conversa infinita: A palavra plural. Tradução de Aurélio Guerra Neto. São Paulo: Escuta, 2001.

O livro por vir. Trad. Leyla PerroneMoisés. São Paulo: Martins Fontes, 2005.

La Communauté Inavouable. Paris: Les Éditions de Minuit, 1983.

Rocco, 1987.

O Espaço Literário. Rio de Janeiro:

Une Voix Venue d'Ailleurs. Paris:

Gallimard, 2002.

CHAMPIGNEULLE, B. Histoire de la musique. Paris: Presses Universitaires de France, 1941.

FOUCAULT, M. Estética: Literatura e Pintura, Música e Cinema. Coleção Ditos \& Escritos - Vol. III. Trad. Inês Autran Dourado. Rio de Janeiro: Forense Universitária, 2000.

As Palavras e as Coisas. Uma arqueologia das ciências humanas. São Paulo: Martins Fontes, 1990.

LEONARDI, V. Jazz em Jerusalém: Inventividade e tradição na história cultural. São Paulo: Nankin, 1999.

NIETZSCHE, F. La Gaya Ciência. Madrid: Libsa, 2000.

OLIVEIRA, S. R. de. Literatura e Música. São Paulo: Perspectiva, 2002.

ONNEN, F. Enciclopedia de la musica. Madrid: Afrodisio Aguado, 1967.

PAZ, O. Signos em Rotação. São Paulo:

Perspectiva, 1996.
SAID, E. W. Elaborações Musicais. Trad. Hamilton dos Santos. Rio de Janeiro: Imago, 1992.

TOMÁS, L. Ouvir o Lógos: música e filosofia. São Paulo: EDUNESP, 2002.

VALÉRY, P. Introdução ao Método de Leonardo da Vinci. Rio de Janeiro: Ed. 34, 2006.

Recebido para publicação em 05 maio 2015 Aceito para publicação em 20 jul. 2015. 